\title{
References
}

1. Bendell, T. et al. Benchmarking for competitive advantage. London: Pitman Publishing, 1993

2. First Find Your Bench. Economist, 11 May 1991, p.102.

3. DTI. Managing in the '90s. Best practice benchmarking: an executive guide. DTI, 1994, p.1.

4. Coopers and Lybrand. Survey of benchmarking in the UK. Coopers and Lybrand and the Confederation of British Industry, 1993, p.5.

\section{Developing an effective questionnaire}

\author{
ANNE RUSSELL \\ IME Ltd \\ and \\ MICHAEL SHOOLBRED \\ School of Information Studies \\ University of Central England
}

\section{Summary}

This article describes a project to study the usage patterns of public library services by students of Adult Basic Education (ABE). The article focuses on how the survey instrument was developed and offers some suggestions on questionnaire design. It will be of interest to researchers working with any group for whom completing a questionnaire might be a struggle.

\section{Introduction}

This article has been written for new researchers who are about to embark upon a survey and are interested in techniques to obtain high response rates and valid data. It should be of particular relevance to those who carry out surveys of groups which might include individuals with reading difficulties or others who would not readily complete a questionnaire.

The project stemmed for some MA research carried out by Anne Russell at the University of Central England in $1993^{(1)}$. The project investigated the usage patterns of public library services by ABE students, the aim of the research being to give public librarians new information about an important and poorly documented group - students of adult basic education $(\mathrm{ABE})$.

These are students who do not possess functional literacy, and therefore have major problems with such everyday literacy skills as writing a cheque, or reading a shopping list. Numeracy as well as literacy is included within the term ABE. These individuals are students because they are participating in $\mathrm{ABE}$ schemes, day classes or evening classes at $\mathrm{ABE}$ Centres designed to help them to develop their literacy and numeracy skills. Where do libraries come in? Some libraries have a close liaison with their local ABE Centres, and aim to provide materials, resource packs and cooperative ventures with tutors. Additionally, some ABE students will want to use libraries of 
their own volition, whilst others will be asked to use libraries as part of projects set by their ABE tutor.

At the core of the project was a self-completed questionnaire in which ABE students gave their views of library services and described what contribution the services made to their literacy development. At first sight it seems unusual, if not bizarre, to select a literacy based research tool for communication with students with literacy problems. An interview schedule was developed for initial informal discussions, but a questionnaire was used to collect most of the data. Why wasn't a full interview schedule developed?

There are several cogent reasons. Firstly, a self-completed questionnaire enabled the researcher to reach a much wider geographic base than would have been possible for one unfunded researcher through personal interviews. The researcher was able to use her network of contacts of ABE tutors throughout the country to sample a wide range of ABE centres. Secondly, in the pilot interviews some students had reservations about being interviewed. The questionnaire guaranteed the anonymity of the respondents and encouraged more integrity of response than might well have been achieved through interviews. Thirdly, the semi-structured format of the questionnaire encouraged the $\mathrm{ABE}$ students towrite, to actively participate in a survey that related to their own circumstances. The researcher was keen to get the authentic views of the students through an instrument which would be developed in terms that they could relate to. She hoped that the questionnaire would enhance their self-esteem and encourage them to feel respected and part of the process.

\section{Results}

The results of the survey are interesting in themselves and include the following:

- $\mathrm{ABE}$ students are regular public library users

- They borrow books but are reluctant to use any form of audiovisual materials in libraries

- They experience real difficulties with inadequate signage within the library

The main body of results are only tangential to this article, which is concerned with how the results were obtained. One striking result is the response rate of $70 \%(n=200)$. This article now offers some thoughts on how this high response rate was obtained, and on the process of survey design to ensure validity and authenticity.

\section{Aims of the project's survey design}

The survey design was developed to ensure three things. Firstly reliability, or consistency; secondly the validity of the data collected, that is that the questions would measure what they were intended to measure. Thirdly the authenticity of the data, that is that the questions would give the respondents the maximum assistance in order to document their own opinions.

With survey populations, it is all too easy to make assumptions about the needs and characteristics of the group. Reynolds et al. ${ }^{(2)}$, in their major survey of the literature of pre-testing questionnaires, discovered a 'lack of empirical evidence' in much survey data whilst there was 'an abundance of normative contributions'. This conclusion seems to be reflected in the literature of Adult Basic Education, where researchers do not always appear to have carried out adequate pretesting, and where 'normative contributions' are not always substantiated by findings. This survey aimed to ensure that the data was as reliable, valid and authentic as possible. One key element was pretesting 
the questionnaire.

\section{Pre-testing}

Pre-testing is an essential component in the design of any survey. Every researcher knows this, but it can sometimes be relegated in a pressing time schedule. Pre-testing should contribute to the discovery of more meaningful answers as researchers familiarize themselves with the cognitive and affective characteristics of the sample group. Bauman and Adair note these benefits of thorough pre-testing in their report on ethnographic interviews:

'This approach served two distinct advantages: it increased the legitimacy of anticipated findings when they did emerge, and simultaneously increased opportunities for discovering unexpected themes' ${ }^{\prime(3)}$.

They consistently stress the need for adequate pre-testing in order to avoid language in the questionnaire which does not originate from respondents and which would be alien to that population. This point is a cornerstone of survey design, but also one that it is extremely easy to overlook in practice. Careful survey and instrument design is required in order to achieve an accurate representation of the opinions of respondents.

\section{Language of the questionnaire - avoiding ambiguity}

The avoidance of ambiguity is highlighted by Fowler ${ }^{(4)}$ as the most important issue in survey construction. His concern is with patient satisfaction surveys, but, clearly, the repercussions of using poorly recorded data could be disastrous in many contexts. He states:

'Ideally, they (the questions) should mean the same things to respondents as to the researcher, the person who will interpret the answers' ${ }^{\prime(5)}$.

This ideal should underpin all stages of questionnaire design, from selection of terminology, through phraseology, to layout.

In this $A B E$ research, preliminary interviews with the students and questionnaire pre-testing enabled the researcher to familiarize herself with the appropriate use of terminology, in order to convey depth of concept in an uncomplicated, non-patronizing style. For instance, repetition of vocabulary was employed where possible to reduce the effort required to read and complete the form. Short sentences, as well as careful use of vocabulary helped to achieve this style, as shown in the example below, taken from the final version of the questionnaire:

'When you find what you are looking for, what is it usually like?'

'Just what I was looking for.'

'Not as useful as I had hoped.'

'Not very useful at all.'

'I never find what I am looking for.' 
An understanding of the phrasing of questions is equally vital if appropriate data is to be captured. Once again, during the pre-testing stage, when interviewing students of Adult Basic Education, the care needed to encourage the most thoughtful and frank reply was a constant issue.

For example, the question, 'What would attract you to using a library?' elicited the response of 'nothing' from some students - the question simply did not work. Similarly, the question 'Are the staff helpful?' proved to be too directed, producing little expansion on the scale of 'helpfulness'. More objective wording was also required. The researcher had been reluctant to offer a range of possible answers with the question 'What puts you off?' as this could get in the way of the respondent's own view. From the pre-testing process, five possible responses and a box for 'another reason' plus lines for free text were supplied. Almost half $(45 \%)$ of respondents used the free text lines, so the doubts were unfounded.

Colloquial text is useful to create informality, but can go too far. A question asking 'How do you get on when you go?', was found to require more clarity, as it was rather too colloquial. It was too broad to produce a understandable response.

Replies ranged from 'It's peaceful' to a comment about swing doors! Whilst these types of response might prove to be a useful source for illustrative quotations, they are unlikely to bear much statistical validity and would pose many problems when data is being coded and analyzed. To summarize, the pre-testing period is when researchers can attune themselves to the language of the respondents. Writing witty advice for parapsychologists, Blackmore stresses the importance of appropriate terminology and not stereotyping respondents:

'If you provide a list of types of ghost, some people's won't fit any category. And believe me, if you put an extra line saying 'None of these - please describe ... you may get lots of checks, but you'll get very few comprehensible answers' ${ }^{\prime(6)}$.

\section{Design features of the questionnaire}

Several special design features were incorporated into the $A B E$ questionnaire in order to accommodate the cognitive and affective characteristics of the sample group. The researcher drew on her experience of working with $\mathrm{ABE}$ students when designing these special features. These were designed to yield a high response rate and to offer the respondents maximum opportunities to provide valid and authentic data. These features included:

- $\quad$ Large typesize (16 point) with bold print, as many ABE students are partially sighted. 16 point is the minimum recommended by the Royal National Institute for the Blind for work with partially sighted groups.

- Colour coded pages to ease navigation around the questionnaire by distinguishing between sections

- $\quad$ Dotted guiding lines for responses to qualitative questions

- Upper case type reduced to a minimum to assist reading. There is a body of research which indicates that lower case type is significantly easier to read then upper case. This applies to all readers and not just $\mathrm{ABE}$ students ${ }^{(7)}$ 
- Hand drawn boxes rather than computer produced ones, to encourage a feeling of "unstuffiness" and informality

- Consistent symmetrical layout down the page to help respondents to follow the text

- Design reflecting the tone of questionnaire, that is, businesslike but informal

Some or all of these recommendations may be useful in other survey contexts, but the universal point to emphasize here is that researchers should customize their work according to their survey population. The questionnaire needs to be designed to include all the factors which will communicate the authentic voice of the respondent. This requires design and language skills, but not necessarily professional design skills. Interestingly, one large scale study on the design of questionnaires tentatively suggests that although design can make a major difference to response rate, professional design by a design agency may make no difference to that response rate ${ }^{(8)}$. The questionnaire will be greatly enhanced by active pre-testing and attention to both the language and the design of the instrument. This particular survey raised several other issues, amongst which is the issue of reciprocity.

\section{Reciprocity}

The area of reciprocity between researcher and respondent is an interesting one, for reciprocity can be a major factor in the success of a survey. By reciprocity, we mean some form of mutually beneficial relationship, or perhaps some sort of bargain between the researcher and respondent. Its aim is to improve the response rate and the quality of the response. As examples of reciprocity in action, Hopkins and Gullickson ${ }^{(9)}$ describe the effectiveness of gratuities, including one survey in which the response rate increased by $19 \%$ when monetary inducement was offered. In another case, Marshall and Rossman ${ }^{(10)}$ quote examples of reciprocity between researchers and drug users. Reciprocity is most often observed in commercial research, where incentives are common. Respondents may, for instance, be promised inclusion in a prize draw in return for their participation.

However, this approach is largely unexploited in non-commercial research. Patton ${ }^{(11)}$ recognizes the importance of the relationship between researchers and their respondents, stating that trust, respect and cooperation from the researcher engenders a reciprocal contract. This can be taken one step further by seeking out mutually beneficial arrangements. In the ABE case study, for example, students used the questionnaires as an exercise to gain accreditation for a City and Guilds certificate. The reciprocal contract should not be permitted to jeopardize the validity of the data, but when properly applied, it may ensure both a high response rate and encourage respondents to have a sense of being involved in a meaningful activity.

\section{Conclusions}

The thrust of this article has been to suggest that all researchers in the social sciences, and especially inexperienced researchers, can benefit by ensuring that their survey instruments are developed from close contact with the survey population. Researchers are well placed to obtain meaningful data through adequate pre-testing and through attention to both the language and the design of their survey tools. This will not only result in the collection of appropriate data, but also demonstrates respect for the respondents. Capturing the expression of authentic and individual experiences and opinions is a planned and systematic process. 


\section{References}

1. Russel, A. Students of Adult Basic Education and public libraries: a user based exploration into ways of improving library provision. University of Central England, 1993. (MA thesis).

2. Reynolds, N., Diamantopoulos, A. and Schlegelmilch, B. Pre-testing in questionnaire design: a review of the literature. Journal of the Market Research Society, 35, 1993, p.171.

3. Bauman, L. and Adair, E. The use of ethnographic interviewing to inform questionnaire construction. Health Education Quarterly, 19, 1992, p.15.

4. Fowler, F. How unclear terms affect survey data.Public Opinion Quarterly, 56, 1992, p. 219.

5. Fowler, F. ibid., p.219.

6. Blackmore, S. Some advice on questionnaire research. Parapsychology Review, 16 (5), 1985, p.6.

7. Felker, D. et al. Guidelines for document designers. American Institute for Research, 1981, p.88.

8. Jansen, J. The effect of questionnaire layout and the size and issue involvement on response rate in mail surveys. Perceptual and Motor Skills, 61, 1985, pp.139-142.

9. Hopkins, $\mathbf{K}$. and Gullickson, A. Monetary gratuities. Journal of Experimental Education, 61, 1992, pp.52-62.

10. Marshall, C. and Rossman, G. Designing qualitative research. London: Sage, 1989, p.69.

11. Patton, M.Q. Qualitative evaluation and research methods. London: Sage, 1990, p.49. 